\title{
Gêneros de texto e multimodalidade ${ }^{1}$
}

\section{Genre and multimodality}

Géneros de texto y multimodalidad

\section{Resumo}

Nesse artigo temos por objetivo discutir a noção de gêneros discursivos defendida por Bakhtin (2003) e conceitos de multimodalidade e texto multimodal propostas por Rojo (2010) que estão presentes no campo social dos gêneros discursivos. A pesquisa tem caráter bibliográfico e, como base teórica, foram utilizados autores como Rojo (2009), Bakhtin (2003), Marcuschi (2008), Motta-Roth (2008), entre outros. Os resultados do debate proposto neste trabalho versaram sobre a relevância para análise no contexto de multiletramento. Por fim, vale ressaltar, que a inserção de gêneros multimodais em sala de aula auxilia no desenvolvimento de competências e habilidades dos alunos em diversas situações de comunicação.

Palavras-chave: Realidade escolar; Gêneros de texto; Multimodalidade.

\begin{abstract}
This article is a bibliographic review that aims discuss the notion of discursive genres defended by Bakhtin (2003). Specifically the aim is approach the multimodality and multimodal texts concept that is proposed by Rojo (2010) that present in the social field of discursive genres. This research has a bibliographic character and theoretical basis the according authors such as Rojo (2009), Bakhtin (2003), Marcuschi (2008), Motta-Roth (2008), among others. The results of the debate proposed in this paper approach the relevance of the work selected for analysis in the context of multiliteracy. Finally, it is mentioned that an insertion of textual genres in the classroom support in individual construction that can to interpret and questioned in different digital media or communication situations.
\end{abstract}

Keywords: School reality; Genres; Multimodality.

\section{Resumen}

En este artículo pretendemos discutir la noción de géneros discursivos defendida por Bakhtin (2003) y los conceptos de multimodalidad y texto multimodal propuestos por Rojo (2010) que están presentes en el campo social de los géneros discursivos. La investigación tiene carácter bibliográfico y, como base teórica, se utilizaron autores como Rojo (2009), Bakhtin (2003), Marcuschi (2008), Motta-Roth (2008), entre otros. Los resultados del debate propuesto en este trabajo abordaron la relevancia para el análisis en el contexto de la multialfabetización. Finalmente, cabe mencionar que la inserción de géneros multimodales en el aula ayuda en el desarrollo de las habilidades y habilidades de los estudiantes en diferentes situaciones comunicativas.

Palabras clave: Realidad escolar; Géneros textuales; Multimodalidad.

\section{Introdução}

Nas últimas décadas, o crescente desenvolvimento das novas Tecnologias de Comunicação e Informações (TIC) na sociedade tem destacado a necessidade de a escola adequar-se à nova realidade tecnológica. Dessa forma, a evolução

\footnotetext{
${ }^{1}$ Artigo realizado na disciplina de Linguagens e Tecnologias Aplicadas ao Ensino do Mestrado Acadêmico em Ensino de Humanidades e Linguagens da UFN.
} 
tecnológica impacta não apenas o ambiente escolar, mas também a prática docente, uma vez que faz circular novos e reconfigurados gêneros de texto, tendo como característica principal a multimodalidade, e, consequentemente, há necessidade de novos letramentos.

Os textos multimodais são aqueles que empregam mais de um tipo de código semiótico para construir seu sentido. São exemplos desses textos os que circulam nas redes sociais, cuja comunicação se dá não apenas por texto escrito, mas também por imagens e vídeos. Pode-se afirmar que esses textos fazem parte do cotidiano da maioria dos jovens estudantes, e até mesmo de seus professores e pais. Por esse motivo, é grande a discussão por parte dos educadores sobre a importância do trabalho com textos multimodais dentro da sala de aula, em suas mais diversas semioses e linguagens.

De acordo com os estudiosos que defendem essa prática, o debate acerca desses textos facilita a aproximação do conteúdo abordado na escola à realidade do estudante, pois envolve uma temática reconhecida e presente nas vidas dos discentes. Além disso, trabalhar com textos multimodais influência de forma direta a construção de sujeitos multiletrados, capazes de desenvolver senso interpretativo e crítico em diversas situações nos mais variados contextos.

A emergência dessa temática justifica a relevância deste artigo, que tem o objetivo de aliar os conceitos de gêneros discursivos, provenientes da teoria bakhtiniana, às noções desenvolvidas por outros pensadores. Além disso, pretende-se fortalecer o trabalho com as novas práticas de letramento que emanam do atual contexto histórico e social: a hipermodernidade. Esse panorama serve como fundamento filosófico e sociológico para as discussões que inserem os textos multimodais e hipermidiáticos em diferentes situações comunicativas na pauta de atualização do ensino escolar.

Este artigo se dividirá em três partes distintas. Em um primeiro momento, será discutido o conceito de gêneros discursivos, proposto por Bakhtin. Nesta etapa do trabalho, também serão destacadas considerações de Motta-Roth e Marcuschi, entre outros estudiosos do campo.

A segunda etapa será dedicada às noções de textos multimodais. Para isso, o trabalho também abordará aspectos e características pertinentes à definição de multimodalidade. Nesse ponto, autores como Rojo e Soares serão de grande valia para dar embasamento teórico ao artigo.

Por fim, as considerações finais apresentarão as conclusões a que as autoras chegaram após a discussão realizada ao longo do desenvolvimento do artigo. Elas versam sobre a importância dos gêneros multimodais e sua inclusão à realidade escolar do aluno.

\section{A Noção de Gêneros de Texto na Perspectiva Bakhtiniana}

Gêneros de texto são manifestações verbais, tanto na linguagem oral quanto na linguagem escrita. No Brasil, Mikhail Bakhtin tem sido um dos autores mais citado pelo seu profundo estudo acerca dos gêneros que ele denomina de discursivos. Estes são considerados, por Bakhtin (2003), como "entidades que funcionam em nossa vida cotidiana ou pública, para nos comunicar e para interagir com as outras pessoas" e poder ser conceituados como tipos "relativamente estáveis de enunciados". Sobre a linguagem, o autor postula que:

A fala só existe, na realidade, na forma concreta dos enunciados de um indivíduo: do sujeito de um discurso-fala. O discurso se molda sempre à forma do enunciado que pertence a um sujeito falante e não pode existir fora dessa forma. Quaisquer que sejam o volume, o conteúdo, a composição, os enunciados sempre possuem, como unidades da comunicação verbal, características estruturais que lhes são comuns, e, acima de tudo, fronteiras claramente delimitadas (Bakhtin, 2003, p. 282).

Em seus trabalhos, Bakhtin também conceitua o texto, que se constitui pelos seus elementos extralinguísticos (a sua dimensão social e constitutiva) e está vinculado a outros enunciados. No entanto, o estudioso destaca que a simples junção de 
enunciados não forma um texto. Rodrigues (2014) enfatiza esse ponto ao postular que, para Bakhtin, "o texto (verbal, oral, escrito ou também em outra forma semiótica) é a unidade, o dado (realidade) primário e o ponto de partida para todas as disciplinas do campo das ciências humanas, pelas suas finalidades científicas diversas" (Rodrigues, 2014, p. 158).

Para Bakhtin (2003), os gêneros do discurso apresentam três dimensões: a) os temas, que são os dizeres através dos gêneros; b) a forma composicional, que são as estruturas comunicativas e semióticas compartilhadas pelos textos; e c) as marcas linguísticas, que são as configurações específicas das unidades de linguagem e da forma composicional do gênero. Esses elementos essenciais ocorrem entre o locutor e o interlocutor em uma situação social. A noção de gêneros discursivos considera que os gêneros estão presentes na ação social e são utilizados em diferentes situações sociais por diferentes interlocutores, cumprindo um papel social.

Eles são, portanto, esferas da atividade humana: onde o discurso se realiza, existem diversos e heterogêneos gêneros discursivos que vão desde conversações espontâneas a textos científicos. As manifestações espontâneas são resultado de interações simples ocorridas no cotidiano, denominadas por Bakhtin de gêneros primários. As manifestações mais complexas, as quais constituem-se por padrões linguísticos, são denominadas como gêneros secundários. Em relação a estas manifestações, Bakhtin (2003, p. 263) afirma que

Os gêneros discursivos secundários (complexos - romances, dramas, pesquisas científicas de toda espécie, os grandes gêneros publicísticos, etc.) surgem nas condições de um convívio cultural mais complexo e relativamente muito desenvolvido e organizado (predominantemente o escrito) - artístico, científico, sociopolítico, etc. No processo de sua formação eles incorporam e reelaboram diversos gêneros primários (simples), que se formaram nas condições da comunicação discursiva imediata. Esses gêneros primários, que integram os complexos, aí se transformam e adquirem um caráter especial: perdem o vínculo imediato com a realidade concreta e os enunciados alheios: por exemplo, a réplica do diálogo cotidiano ou da carta no romance, ao manterem a sua forma e o significado cotidiano apenas no plano do conteúdo romanesco, integram a realidade concreta apenas através do conjunto do romance, ou seja, como acontecimento artístico-literário e não da vida cotidiana. No seu conjunto o romance é um enunciado, como a réplica do diálogo cotidiano ou uma carta privada (ele tem a mesma natureza dessas duas), mas à diferença deles é um enunciado secundário (complexo).

O estudo de gêneros não é algo recente. O termo gênero, do latim genus, já era usado no sentido de classificação. Sobre este estudo, Marcuschi (2008, p. 147) informa que

A expressão gênero esteve, na tradição ocidental, especialmente ligada aos gêneros literários, cuja análise se inicia com Platão para se firmar com Aristóteles, passando por Horácio e Quintiliano, pela Idade Média, o Renascimento e a Modernidade, até os primórdios do século XX.

No estudo sistemático de gênero na antiguidade clássica, Platão centrou seu estudo na tradição poética, com os gêneros épico, trágico e cômico. Aristóteles, em seus estudos retóricos acerca de gêneros, conceituou os três elementos que compõem o discurso: "(a) aquele que fala; (b) aquilo sobre o que se fala; e (c) aquele a quem se fala” (Marcuschi, 2008).

Bakhtin propõe, então, uma abordagem conhecida como sociodialógica ou sociodiscursiva, pois, "entende a constituição e o funcionamento dos gêneros com base em sua relação com a situação social de interação e a esfera social de atividade" (Medeiros; Tomasi, 2017). A partir da perspectiva bakhtiniana, surgiram as diferentes abordagens teóricosmetodológicas sobre gêneros, cujas principais são destacadas a seguir. Uma das perspectivas de estudos de gêneros é a sociorretórica. Na perspectiva sociorretórica de caráter etnográfico, voltada para o ensino de segunda língua e desenvolvida por Swales (1990) e Bhatia (1993), o gênero é analisado e identificado por estágios em sua estrutura. Há uma visão nitidamente marcada pela perspectiva etnográfica, com os conceitos de comunidade, de propósito, de atores sociais (Marcuschi, 2008). Essa abordagem tem seu foco na organização retórica dos "tipos de textos, definidos por suas propriedades formais e por seus objetivos comunicativos dentro de contextos sociais" (Motta-Roth, 2008). 
Já a perspectiva sociorretórica/sócio-histórica e cultural de Miller (1984) e Bazerman (1988) foi influenciada não somente Bakhtin, mas também por antropólogos, sociólogos e etnógrafos, os quais possuem "atenção na compreensão do funcionamento social e histórico, bem como sua relação com o poder" (Marcuschi, 2008, p. 153), e nos contextos sociais e nos atos de fala realizados numa dada situação (Motta-Roth, 2008).

A perspectiva interacionista e sociodiscursiva de caráter psicolinguístico e de atenção didática voltada à língua materna, proposta por Bronckart (1999), Dolz e Schneuwly (2004), recebe influências de Bakhtin e Vygotsky. Tem por preocupação maior a "tanto com a oralidade como a escrita. A perspectiva geral é de caráter psicolinguístico ligado ao sociointeracionismo" (Marcuschi, 2008, p. 153).

A abordagem da análise crítica de Fairclough (1992) é uma perspectiva teórica sobre a semiose. Para os teóricos dessa abordagem, o discurso é "uma prática social e o gênero é uma maneira socialmente ratificada de usar a língua como um tipo particular de atividade social" (Marcuschi, 2008).

Por fim, a perspectiva sistêmico-funcional de Sydney, representada por Halliday (1985); Hasan e Martin (1989), se constitui "com foco na léxico-gramática e nas funções desempenhadas por ela nos contextos sociais" (Motta-Roth, 2008). São aspectos importantes para essa abordagem a análise da relação texto e contexto, a estrutura esquemática do texto em estágios, a relação situacional e cultural e o gênero como realização do registo (Marcuschi, 2008).

Os gêneros discursivos são utilizados em todas as disciplinas e áreas do conhecimento pelas necessidades diversas de comunicação. Dentro da diversidade de gêneros discursivos presentes no campo social, estão os gêneros multimodais:

Kress e Van Leeuwen (1996, apud Cavalcante, 2010) refletem acerca da definição de gêneros multimodais. Na ótica dos autores, os gêneros multimodais têm sua materialização fomentada a partir de distintas semioses. Em outras palavras, para que um gênero discursivo obtenha o posto de multimodal, a produção de sentido e de significação é potencializada por diferenciados códigos semióticos. Isso aniquila a perspectiva monomodal. Dessa feita, diante das múltiplas semioses que podem ser mobilizadas na composição textual, um determinado gênero discursivo assume o status de multimodal. (Silva et al., 2016)

Cabe ressaltar, ainda que, para que um gênero discursivo seja um gênero multimodal, ele precisa produzir sentidos e significados por diferentes códigos semióticos. Existem também outras características indispensáveis a um texto para que ele possa ser categorizado como pertencente ao gênero multimodal. Estas serão discutidas na etapa seguinte do trabalho.

\section{Considerações Sobre Multimodalidade e Gêneros Multimodais}

Os gêneros de texto produzem significados e estabelecem relações por meio dos discursos neles veiculados. Esses, por sua vez, materializam-se através da linguagem, seja ela verbal ou não-verbal. Todo o arranjo visual existente no gênero, ou seja, a diagramação, cores, figuras, tipo de papel (no caso de texto escrito), ou até como as pessoas se comportam nos textos orais (gestos, entonação de voz, expressões faciais), convencionou-se chamar de multimodalidade (Ferreira; Bortoluzzi, 2006).

Os gêneros multimodais se potencializaram na pós-modernidade ou modernidade líquida (Bauman, 2007), período que diz respeito a uma nova época em que as relações sociais e econômicas estão em contínua modificação. A troca de sistemas analógicos pelos sistemas digitais na codificação da informação, combinados com o desenvolvimento de novos sistemas de transmissão, cria um novo cenário técnico no qual a informação pode ser operada em maneiras mais flexíveis (Thompson, 1998, p.19). Com esse avanço tecnológico, a sociedade protagoniza mudanças nos hábitos e costumes sociais, pois, o "uso dos meios de comunicação implica na criação de novas formas de ação e de interação no mundo social, de novos tipos de relações sociais" (Thompson, 1998, p.13).

As novas formas de comunicação provenientes da modernidade tecnológica ampliam a cognição dos indivíduos, suas as habilidades, competências e experiências. Nessas novas formas de comunicação, a mensagem tem características comuns, as 
quais permitem a compreensão e entendimento por usuários de diferentes culturas e países. Nesse contexto, a linguagem ganha frequentemente um novo estilo constitutivo, marcado por formas híbridas de textos, que misturam sons, imagens e palavras (recursos verbais e não-verbais), resultando nos textos multimodais.

Um texto, ou enunciado é um dito (ou cantado, escrito ou mesmo pensado) concreto e único, "irrepetível", que gera significação e se vale da língua/linguagem para sua materialização, constituindo o discurso (Rojo, 2012). Visto que um texto é um "evento construído numa orientação multissistemas que envolve tanto aspectos linguísticos como não-linguísticos no seu processamento" (Marcuschi, 2008, p. 80), a multiplicidade de linguagens presentes nos textos configura a multimodalidade desse texto.

A multimodalidade foi definida por Kress e van Leeuwen (2006) como a característica dos textos que utilizam mais de um código semiótico, tais como palavras e imagens. Segundo Rojo (2012), nesses textos, as imagens podem ser estáticas ou em movimento, com áudio, cores, links, e estão disponíveis tanto no suporte digital como na mídia impressa. Essas novas formas de texto originam os novos e reconfigurados gêneros de texto. Essas modalidades,

Os gêneros multimodais estão inseridos nas situações comunicativas em diversos contextos de utilização da língua, eles são "cultural e historicamente constituídos e não podem ser pensados como algo exterior ao contexto de comunicação" (Knoll; Fuzer, 2019). Nesse sentido, os gêneros multimodais, para serem produzidos e/ou compreendidos, exigem do produtor/leitor a aquisição e o desenvolvimento de habilidades e competências de leitura e produção, ou seja, novos (multi)letramentos.

Em seus estudos sobre o discurso multimodal, Kress e van Leeuwen (2006) enfocam imagens estáticas e descrevem as imagens em movimento para compreender a significação dos textos multimodais, já que para ler um texto não se deve prestar atenção somente na mensagem escrita, mas buscar compreender como produtores de textos utilizam a língua em conjunto com outras semioses para produção de sentidos (Kress; Van Leeuwen, 2006). Para a constituição teórica da GDV, os estudiosos oferecem aos estudos da linguagem um conjunto de categorias e análise de textos multimodais por meio de três metafunções: representacional, interacional e composicional. Elas se fundamentam nas relações metafuncionais de usos da língua ideacional, interpessoal e textual, respectivamente - presentes teoricamente na Gramática Sistêmico-Funcional proposta por Halliday (1985) e adaptadas por Kress e van Leeuwen (2006) para a linguagem visual.

As categorias, portanto, devem ser analisadas por suas respectivas metafunções, cita Cunha (2018, p. 65):

como o mundo é e pode ser representado - metafunção representacional -; como os participantes representados interagem entre si e com a realidade constituída, dentro e fora da paisagem semiótica analisada - metafunção interacional -; e como são distribuídos os valores da informação, os tipos de enquadramentos e as relações de polarização esquerda/direita, em cima/embaixo na estrutura de composição da imagem - metafunção composicional.

A Gramática do Design Visual (GDV) propõe ferramentas para descrevermos a forma como itens identificáveis visualmente, tais como "pessoas, lugares e coisas", são arranjados em orações visuais de maior ou menor complexidade e extensão (Kress; Van Leeuwen, 2006, p. 1). A GDV oferece categorias para a análise e a leitura de imagens, que devem ser realizadas no contato com aspectos visíveis ao primeiro olhar do leitor. Em vista disso, aspectos como presença de participantes (humanos ou não) envolvidos em um evento; a presença de vetores indicando ação ou reação; e a inserção dos participantes em um pano de fundo que indique as circunstâncias de tempo e espaço nas quais o evento se desenvolve (Nascimento; Bezzera; Heberle, 2011) são aspectos da metafunção representacional. Os aspectos avaliados na metafunção interacional são o contato do olhar entre o participante representado na imagem e o leitor; a visualização do participante representado como estando próximo ou distante do leitor (Nascimento; Bezzera; Heberle, 2011). Já na metafunção 
composicional, os elementos que constituem o texto e seus respectivos sentidos podem ser observados a partir de três aspectos principais: o valor da informação; o enquadramento da imagem e a saliência (Nascimento; Bezzera; Heberle, 2011).

Todas essas categorias compõem um significado maior que auxilia no desenvolvimento da "competência comunicativa multimodal" (Royce, 2002). Essa competência inclui a habilidade de usar estratégias para interpretar textos compostos por palavras e imagens e habilidade de se comunicar por meio desses textos, tornando-se um indivíduo multiletrado, isso porque a multimodalidade (ou multissemiose) dos textos contemporâneos exigem multiletramentos (Rojo, 2012, p. 19). Dionisio (2010, p. 165) já chamava a atenção para o fato de que

se os gêneros se materializam em formas de representação multimodal (linguagem alfabética, disposição gráfica na página ou na tela, cores, figuras geométricas etc.) que se integram na construção do sentido, o conceito de letramento também precisa ir além do meramente alfabético. Precisamos falar em multiletramento!

Para a compreensão do conceito de multiletramentos, é necessário que se saiba, primeiro o que é letramento. O letramento é definido por Soares $(2007$, p. 18) como resultado da ação de ensinar ou de aprender a ler e escrever, ou seja, “o estado ou a condição que adquire um grupo social ou um indivíduo como consequência de ter-se apropriado da escrita". Ainda segundo Soares (2004), a pessoa alfabetizada é a que domina as habilidades básicas ou iniciais de leitura e de escrita, mas a pessoa letrada é aquela que utiliza as habilidades básicas com desenvoltura em situações sociais concretas.

Já os multiletramentos, segundo Rojo (2009, p. 98), são os usos e práticas sociais de linguagem que envolvem a escrita de uma ou de outra maneira, sejam elas valorizadas ou não valorizadas, locais ou globais, recobrindo contextos sociais diversos (família, igreja, trabalho, mídias, escola, etc.), numa perspectiva sociológica, antropológica e sociocultural. Ou seja, o sujeito multiletrado realiza práticas de compreensão e produção de novas ferramentas usadas para produção de linguagens. Essas ferramentas incluem diversas mídias, como a física e a digital. Diferentemente das mídias anteriores (impressas e analógicas), a mídia digital permite que o usuário interaja em vários níveis e com vários interlocutores (Rojo, 2009, p. 23). Para realizar práticas de compreensão e escrita de gêneros multimodais, Dionísio, Vasconcellos e Souza (2014) ressaltam a importância de avaliar

a relação da imagem com o gênero (é um livro de narrativas? é um livro de poemas? é um livro de adivinhas?), qual a função das imagens na construção do livro? Se o livro é de natureza didática, devemos ter uma noção clara das convenções das linguagens, dentre elas a fotografia, o desenho, as linhas, para ciências como a Biologia, a Matemática, a História, a Química etc. Observar a cumplicidade entre gênero textual, linguagens e áreas do conhecimento é fundamental, visto que gráficos, tabelas, mapas, desenhos anatômicos, por exemplo, apresentam convenções que vão além das do sistema linguístico. (Dionísio; Vasconcellos; Souza, 2014, p. 14)

Na sociedade pós-moderna, os sujeitos precisam construir sentidos a partir da "multiplicidade de símbolos, sinais gráficos, imagens, sons, texturas presentes cotidianamente"' (Bevilaqua; Colaço, 2012, p.21). A modernidade líquida modificou as relações sociais, econômicas, culturais e, consequentemente, as práticas escolares. Sendo assim, a educação deve objetivar a capacitação dos alunos, auxiliando no exercício da cidadania, com uma postura ativa e crítica diante de tais mudanças.

No Brasil, é constante a preocupação com o ensino escolar público. O principal índice indicador de qualidade da educação brasileira, o IDEB (Índice de Desenvolvimento da Educação Básica) é calculado a partir dos dados sobre aprovação obtidos no Censo Escolar e das médias de desempenho obtidas no Sistema de Avaliação da Educação Básica (Brasil, 2019), sendo que nenhum estado atingiu as metas esperadas para o Ensino Médio em 2017 e 2019, dois últimos anos de avaliação do indicador. Nessas condições, a escola e os professores buscam frequentemente aprimorar as suas práticas pedagógicas para adequar o ensino às modificações na sociedade atual. Tendo em vista essas preocupações, entrou em vigor, no ano de 2017 , a 
Base Nacional Comum Curricular (BNCC). Este é um documento de caráter normativo que assegura os direitos dos alunos à aprendizagem e ao desenvolvimento, em conformidade com o que preceitua o Plano Nacional de Educação (PNE). A BNCC está orientada pelos princípios éticos, políticos e estéticos que visam a formação humana integral e a construção de uma sociedade justa, democrática e inclusiva. Na cultura digital e nos avanços da tecnologia de informação e comunicação da sociedade contemporânea, os jovens:

têm se engajado cada vez mais como protagonistas da cultura digital, envolvendo-se diretamente em novas formas de interação multimidiática e multimodal e de atuação social em rede, que se realizam de modo cada vez mais ágil. Por sua vez, essa cultura também apresenta forte apelo emocional e induz ao imediatismo de respostas e à efemeridade das informações, privilegiando análises superficiais e o uso de imagens e formas de expressão mais sintéticas, diferentes dos modos de dizer e argumentar característicos da vida escolar (BNCC, 2017, p. 61).

Por isso, é importante que as instituições escolares preservem suas contribuições para o desenvolvimento crítico e reflexivo do aluno acerca da variedade de conteúdos midiáticos e digitais. Também é imprescindível que a escola:

compreenda e incorpore mais as novas linguagens e seus modos de funcionamento, desvendando possibilidades de comunicação (e também de manipulação), e que eduque para usos mais democráticos das tecnologias e para uma participação mais consciente na cultura digital. Ao aproveitar o potencial de comunicação do universo digital, a escola pode instituir novos modos de promover a aprendizagem, a interação e o compartilhamento de significados entre professores e estudantes (BNCC, 2017, p. 61).

$\mathrm{Na}$ área das linguagens e suas tecnologias, a BNCC (2017) postula sobre a importância do trabalho com as práticas de linguagem: são elas que garantem aos estudantes oportunidades de experienciar fazeres cada vez mais próximos das práticas da vida acadêmica, profissional, pública, cultural e pessoal. Estes jovens, ao explorarem as possibilidades expressivas das diversas linguagens, se tornam aptos a realizar reflexões que envolvam o exercício de análise de elementos discursivos, composicionais e formais de enunciados nas diferentes semioses (BNCC, 2017, p. 486).

No contexto da cultura digital, os gêneros de texto organizam-se de maneira híbrida e multissemiótica: as práticas sociais da leitura e da escrita estão atreladas ao uso e ao significado a partir dos contextos socioculturais em que os enunciados são produzidos, sendo eles indissociáveis da produção dos discursos. Levando em consideração o atual momento tecnológico vivenciado, as práticas discursivas que transitam no ambiente virtual estão sendo constantemente ressignificadas sob a forma de textos "organizados com som, imagem, movimentos, escrita e outras linguagens" (Rojo; Moura, 2012, p. 151). Sendo assim, o gênero multimodal como instrumento semiótico está ressignificando as práticas de leitura e produção de textos discursivos.

\section{Considerações Finais}

As noções discutidas e abordadas até este ponto do artigo dão conta dos conceitos e abordagens de estudo de gêneros de texto, e suas relações com a multimodalidade. Os gêneros multimodais são instrumentos úteis e efetivos para a tarefa do professor de aproximar o conteúdo abordado na escola à realidade vivenciada pelo discente, que utiliza seus conhecimentos prévios para construir novos saberes e oportunidades. O resultado da inserção desses gêneros em sala de aula é a transformação da escola em um ambiente em que circulam de forma significativa e pertinente os multiletramentos, o acesso ao conhecimento e à informação.

Para concretizar a proposta de implementação dos multiletramentos na escola, é preciso que o educador tenha conhecimento das novas mídias consolidadas na sociedade. Assim, ele pode trabalhar em suas aulas a diversidade de gêneros textuais, seus suportes, suas linguagens e suas particularidades. Para isso, o professor precisa conhecer as propriedades e 
características dessas linguagens, bem como uma maneira efetiva de inseri-las no contexto de suas turmas, pensando nas especificidades de cada uma. Além disso, é necessário que a instituição de ensino forneça o suporte e o espaço necessários para a capacitação do educador e também para que ele possa inserir as tecnologias em seus programas escolares.

É preciso ter em mente que a modernidade e as inovações tecnológicas estão ressignificando as relações sociais: novas formas de comunicação estão surgindo constantemente. Consequentemente, a escola está imersa nesse cenário de novas práticas sociais e discursivas. O último documento norteador educacional, a BNCC, foi publicado para auxiliar o trabalho da escola e do professor com a prática docente no desenvolvimento integral do aluno na era tecnológica.

\section{Referências}

Bakhtin, M. (2003). Estética da criação verbal. Martins Fontes.

Barros, D. E. C. (2010). Gêneros gramatical, textual e social nos estudos linguísticos. Acta Scientiarum. Language and Culture, Maringá, $32(2), 181-189$.

Bauman, Z. Tempos líquidos. Tradução de Carlos Alberto Medeiros. Jorge Zahar, 2007.

Bevilaqua, R.; Colaço, S. F. (2012). Letramentos na contemporaneidade: perspectivas teóricas. In: Pinto, C. M. et al. (Orgs.) Projetos de letramento: debates e aplicações. São Vicente do Sul: Instituto Federal Farroupilha, p. 21-37.

Costa, R. P., \& Calhau, S. (Org.). (2010) ...E uma educação pro povo, tem? Caetés.

Cunha, A. H., \& Cunha, C. M. P. (2018) Reflexões sobre a relação palavra imagem em processos de leitura e produção escrita: u ma proposta com tiras da turma do Xaxado. In: Ferreira, L. A. (Org.) Retórica, Escrita e Autoria na Escola. Blucher. 113 -126.

Dionísio, A. P., Vasconcelos, L. J., \& Souza, M. M. (2014). Multimodalidades e leituras: funcionamento cognitivo, recursos semióticos, convenções visuais. Recife: Pipa Comunicação.

Ferreira, J. C., \& Bortoluzzi, V. I.(2006) Estudos em multimodalidade: a multimodalidade em capas de revista de auto-ajuda.

Ferreira, L. A. (2018). Retórica, Escrita e Autoria na Escola. Blucher.

Ferreira, M. (2011). Estudo dos gêneros: uma perspectiva evolutiva. Diálogo e Interação, 5. http://www.faccrei.edu.br/dialogoeinteracao.

Knoll, G. F, \& Fuzer, C. (2019). Análise de infográficos da esfera publicitária: multimodalidade e metafunção composicional. Alfa, 63(3), 589-612. Kress, G., \& Van Leeuwen, T. (2006). Reading images: the grammar of visual design. London: Routledge.

Medeiros, J. B., \& Tomasi, C. (2017). Como escrever textos: gêneros e sequências textuais. Atlas.

Meurer, J. L., Bonioni A., \& Motta-Roth, D. (Orgs.). (2005). Gêneros: teorias, métodos, debates. Parábola Editorial.

Ministério da Educação. 2017. Base Nacional Comum Curricular (BNCC) 2017. http://basenacionalcomum.mec.gov.br/.

Motta-Roth, D. (2008). Análise crítica de gêneros: contribuições para o ensino e a pesquisa de linguagem. Delta, 2(24), $341-383$.

Nascimento, R. G., Bezerra, F. A. S., \& Heberle, V. M. (2011). Multiletramentos: iniciação à análise de imagens. Linguagem \& Ensino, Pelotas, 14(2), 529552.

Rojo, R. H. R. (2010). Alfabetismo(s), letramento(s), multiletramento(s): desafios contemporâneos à Educação de Adultos. In: Costa, R. P., \& Calhau, S. (Org.) ...E uma educação pro povo, tem? Rio de Janeiro: Caetés. 75-90.

Rojo, R. H. R. (2005). Gêneros do discurso e gêneros textuais: questões teóricas e aplicadas. In: Meurer, J. L., Bonioni A., \& Motta-Roth, D. (Orgs.) Gêneros: teorias, métodos, debates. São Paulo: Parábola Editorial. 184-207.

Rojo, R. (2009). Letramentos múltiplos, escola e inclusão social. Parábola.

Rojo, R., \& Moura, E. (2012). Multiletramentos na escola. Parábola.

Royce, T. (2002). Multimodality in the TESOL Classroom: Exploring VisualVerbal Synergy. TESOL Quarterly, $36,2: 191$ - 205.

Silva, S. P. et al. (2015). O anúncio publicitário na sala de aula: práticas de leitura, produção de texto e oralidade em foco. Philologus, 63, $1.364-1.386$. http://www.filologia.org.br/rph/ANO21/63supl/098.pdf.

Soares, M. (2004). Letramento e alfabetização: as muitas facetas. Revista Brasileira de Educação, 25, 5-17.

Soares, M. (2010). Letramento: um tema em três gêneros. Autêntica.

Thompson, J. B. (1998). A mídia e a modernidade: uma teoria social da mídia. Vozes. 
Research, Society and Development, v. 10, n. 1, e14610111255, 2021

(CC BY 4.0) | ISSN 2525-3409 | DOI: http://dx.doi.org/10.33448/rsd-v10i1.11255

Vieira, J., \& Silvestre, C. (2015). Introdução à multimodalidade: contribuições da Gramática Sistêmico-Funcional, Análise de Discurso Crítica, Semiótica Social. J. Antunes Vieira. 